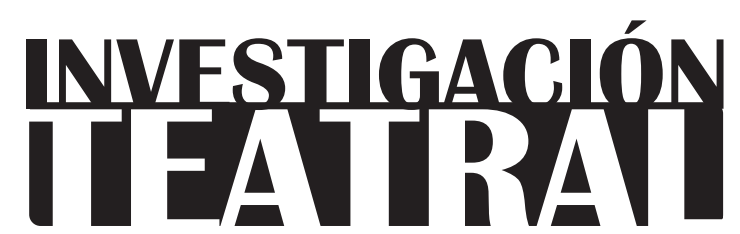

Revista de artes escénicas y performatividad

Vol. 10, Núm. 16

octubre 2019-marzo 2020

Segunda época

Reseña del libro:

ISSN impreso: 1665-8728

ISSN electrónico: 2594-0953

Universidad Veracruzana

\title{
El arte de actuar identidades y rituales. Hacia una antropología del teatro indigena en México, de Elizabeth Araiza Hernández
}

\author{
Alejandro Ortiz Bullé-Goyri*
}

\footnotetext{
* Universidad Autónoma Metropolitana-Azcapotzalco, México.

e-mail: ortizote@correo.azc.uam.mx
}

Recibido: 25 de marzo de 2019

Aceptado: 06 de agosto de 2019

Doi: 10.25009/it.v10i16.2612 


\section{El arte de actuar identidades y rituales. Hacia una antropología del teatro indígena en México, de Elizabeth Araiza Hernández}

Araiza Hernández, Elizabeth. El arte de actuar identidades y rituales. Hacia una antropología del teatro indígena en México. Zamora: El Colegio de Michoacán, 2016, 340 pp.

$\mathrm{P}$ oco a poco, los llamados estudios culturales y los estudios en artes escénicas se han ido ocupando de estudiar y configurar el espectro de las manifestaciones escénicas emergentes y alternativas. En efecto, hay pocos estudios académicos, pero el interés se ha ido acrecentando. Vale la pena registrar, aquí, tres ejemplos importantes de investigaciones en ese sentido: el trabajo de Donald Frischmann ${ }^{1}$ y sus distintos acercamientos al teatro popular mexicano; el de Tamara Underiner, ${ }^{2}$ enfocado a las nuevas perspectivas del teatro maya, así como el trabajo de Israel Franco ${ }^{3}$ en los terrenos del teatro comunitario, en México.

Por ello, celebramos la aparición de este importante estudio de Elizabeth Araiza sobre estas expresiones teatrales. Originalmente, Araiza tiene una formación de etnóloga por la Escuela Nacional de Antropología e Historia. Posteriormente, realizó estudios en Francia; primero, con Daniel Meyran, en el Centro de Estudios Ibéricos y Latinoamericanos de la Universidad de Perpignan, luego, realizó un doctorado con Jean Pradier, en la Universidad de Paris 8, en Etnoescenología. Este libro es resultado de un trabajo dedicado, como investigadora en el ámbito documental, de reflexión teórica y de campo, como se va constatando a lo largo de sus distintos capítulos.

1 Frischmann, Donald H. El nuevo teatro popular en México. México: INBA/Centro Nacional de Investigación, Documentación e Información Teatral “Rodolfo Usigli”, 1990.

2 Underiner, Tamara L. Contemporary Theatre in Mayan Mexico: Death-Defying Acts. Austin: University of Texas Press, 2004.

3 Franco, Israel, coord. Teatro Comunitario. @Cuaderno de investigación [CD-rom]. México: INBA/Centro Nacional de Investigación, Documentación e Información Teatral "Rodolfo Usigli"/Conaculta, 2010. 
En su prólogo al libro de Elizabeth Araiza, el antropólogo Rodrigo Díaz hace, de entrada, una valoración muy generosa que luego uno, como lector, habrá de constatar:

Para cada caso se exponen y razonan los argumentos que justifican la clasificación, también el desarrollo histórico e institucional de cada categoría, reseñas e imágenes de obras de teatro, y cuando se hace necesario, la autora, no rehúye a la polémica ante otras posiciones descriptivas y analíticas. Al final nos invita a ampliar el estudio de las interrelaciones entre teatro y ritual más vasto de Latinoamérica, esto es, nos convoca a un análisis comparativo. Comienza a disfrutar, amable lector, este creativo libro (22).

Y sí, en efecto, la lectura de este libro puede producir un deleite. No es que se lea como una novela, pero es claro que su complejidad y la mirada con que aborda las interacciones e intersecciones entre teatralidad y ritualidad, o las confrontaciones entre teatro indigenista, indianista, indígena, no indígena, indígena campesino y demás, son apasionantes, tanto por los modelos y ejemplos que toma como por la mirada compleja con que la autora observa su objeto de estudio.

El propósito del libro no es, específicamente, abordar la antropología del teatro indígena en México como tal o de manera general. Más bien, la autora, Elizabeth Araiza, se esmera en enfocar su estudio en los aspectos relativos a las construcciones de identidades y a la manera como ideológicamente el sujeto "indígena" es representado a través del arte teatral, bajo distintos contextos, enfoques y perspectivas. Esto le da riqueza al libro en su construcción caleidoscópica. Podría parecer caótica esta percepción, pues lo mismo aborda la imagen que la cultura dominante construye de la noción de indígena, como el uso ritualístico que se hace del lenguaje teatral en algunos grupos étnicos. El ritual teatralizado -aspecto que parece una tautología, pero no lo es, en la medida en que los campos de la representación teatral y de la representación ritual contienen en sí mismos sus propias normas y presupuestos- es analizado por nuestra autora con ejemplos muy eficaces para entender el fenómeno.

El arte de actuar identidades y rituales está organizado en cinco capítulos:

1. Una persuasiva verosimilitud o las fuentes arqueológicas e históricas sobre el teatro aztequista.

2. Bajo un signo educativo y cívico. Sobre el teatro indigenista.

3. Campesinos antes que indígenas, las vertientes campesinistas.

4. Un teatro ritual.

5. El ethos del teatro indígena contemporáneo. 
Además, incluye una necesaria Introducción, en donde asienta las bases metodológicas de su estudio, así como unas Notas finales con su respectiva bibliografía, sin faltar unos muy útiles índices de ilustraciones, temático y onomástico. Con ello se muestra la complejidad y amplitud del trabajo de investigación y de reflexión a propósito de este campo cultural, prácticamente inexplorado, salvo por algunos casos particulares.

Pero habrá que retomar algunas de las preguntas sustantivas que Araiza se hace para desarrollar su investigación: “¿Por qué la representación teatral de los indígenas se ha enfocado sobre todo en aquello que concierne al dominio del ritual, las ceremonias, las fiestas y las danzas? ¿Qué relación hay entre ritual e identidad, teatro e identidad y entre ritual llevado sobre una escena teatral y la identidad sea étnica o nacional?" (25-26).

En el camino por responder a estas preguntas, podemos encontrar ejemplos de teatralización de la noción de indígena desde muy amplias y diversas perspectivas, como es el caso de las experiencias de teatro aztequista, tanto desde el contexto novohispano, como en el de la pretendida reivindicación de "lo indígena" en el México posrevolucionario, así como en representaciones de distinta índole en ámbitos teatrales convencionales, como en el Teatro Principal de la Ciudad de México; en la obra dramática del etnólogo, literato e historiador del siglo xIX, Alfredo Chavero, o en experiencias operísticas, como fue el caso de Atzimba, de Ricardo Castro, con libreto de Alfredo Michel, estrenada en el Teatro Arbeu de la Ciudad de México el 21 de enero de 1900. Esta última presenta una trama que confronta a la cultura purépecha oprimida y el imperio español conquistador, a través de la historia de amor entre una princesa tarasca y un oficial español de las huestes de Cortés. ${ }^{4}$

¿Y qué decir de las representaciones de aspectos rituales y espectaculares dirigidas por Soledad Ruiz para el Teatro Conasupo de Orientación Campesina con la brigada Xicoténcatl (184-187)? Con ello, podríamos hacernos el siguiente cuestionamiento: ¿al teatro de evangelización del siglo xvi puede considerársele indígena? Sobre el teatro de María Alicia Martínez Medrano y su laboratorio de Teatro Indígena y Campesino de Tabasco, ¿se puede decir que fue "auténticamente" indígena? Elizabeth Araiza no necesariamente responde a estas interrogantes, pero, en cambio, reflexiona con nítida claridad en torno a los problemas identitarios que estas experiencias teatrales han significado.

Hay, en el libro, dos aspectos que me resultan particularmente apasionantes por su sentido propositivo: el primero es el capítulo "Un teatro ritual", en donde la autora va desmadejando la urdimbre entre la ritualidad y la teatralidad que suele haber en las prácticas escénicas de comunidades indígenas. Araiza explica, ejemplifica, comenta y nos pone en

4 Manuel Mañón, en su Historia del Teatro Principal, da cuenta de otra zarzuela azquequista: "El hijo del Sol ... zarzuela de costumbres aztecas, libro de Castillo y Best con música de Barajas, se estrenó el sábado 21. No tuvo éxito, se retiró a la tercera función" (391). 
perspectiva la complejidad del fenómeno; nos damos cuenta, como lectores, de lo importante que significa que expresiones culturales, como el teatro, sean estudiados y analizados desde la antropología y no sólo desde el propio ámbito de la teatrología. Entiendo que ambos se complementan e infiero, por ello, que el libro es, justamente, un encuentro muy afortunado entre ambas disciplinas.

El segundo punto es en cuanto a las interacciones entre representación teatral, como experiencia de mímesis, y la práctica ritual, como experiencia iniciática. Elizabeth Araiza tiene claro cuál es el sentido de su indagación. No es que forzosamente esté buscando elementos rituales en la representación teatral; su noción de teatro-rito va más allá de lo que ella misma observa en la definición de Lévi-Strauss, en cuanto a que no necesariamente las experiencias de teatro indígena establecen, como patrón, la "puesta en escena de una narración mítica" (189). Sin embargo, es claro que también observa que la misma actividad teatral puede llegar a formar parte de prácticas rituales claramente establecidas en los códigos culturales de una determinada comunidad, como es el caso de la experiencia que refiere en San Miguel Cajonos, población zapoteca que asume la representación teatral, las "comedias", justamente como un elemento fundamental para una práctica de rito de iniciación o de pasaje, o como lo afirma la propia Elizabeth Araiza:

El éxito de la fiesta en honor de la Inmaculada se debía en gran medida a este fenómeno completamente inesperado, totalmente nuevo que consistía en integrar unas obras teatrales como parte del sistema de acciones rituales y festivas [...] No obstante las comedias no nacen bajo un signo ritual, sino que lo adquieren (223).

Y, más adelante, recoge un testimonio al respecto:

Cabe citar el testimonio de doña Mathilde Jiménez, quien a sus 76 años conserva aún frescos en su memoria detalles significativos de su participación: "Yo también actué en las comedias, de hace ya mucho tiempo pues yo era muy joven, acepté participar para agradecer a la virgencita, porque ella hace milagros, le hacemos sus comedias para que ella esté contenta en su fiesta, para alegrar su fiesta" (225).

De manera que para tener el privilegio de representar "comedias" se requiere, necesariamente, no sólo de aptitudes, sino también de una predisposición para asumir responsabilidades que van aunadas al sentido histriónico. Dice Elizabeth Araiza: "Al interpretar uno de los papeles de las comedias, al actuar en público, los jóvenes están demostrando tener suficiente madurez psicológica, emocional e intelectual como para asumir un cargo, con toda la responsabilidad que esto implica" (231). 
Mucho más se puede comentar, especialmente en cuanto a sus reflexiones en torno a la práctica teatral indígena contemporánea, pero bástenos decir que la autora nos plantea que no existe una determinada "pureza" en las experiencias de teatro en los ámbitos indígenas en México, ni tampoco una univocidad. Más bien, nos presenta, con sus propios testimonios y contrastaciones, un universo diverso y multidimensional, que va desde el uso del teatro para la lucha social, hasta las apropiaciones de modelos aparentemente ajenos como puede ser Jesucristo Super Star, coexistiendo con las representaciones tradicionales de la Pasión de Cristo. El trabajo de Araiza nos permite asumir que, en el estudio y documentación de este ámbito de expresiones escénicas, hace falta mucho por recorrer y reflexionar. 